\title{
The Evolution of Cyanobacteria Bloom Observation in the Baltic Sea
}

By Lumi Haraguchi, Sirpa Lehtinen, Jenni Attila, Hanna Alasalmi, Matti Lindholm, Kaisa Kraft, Otso Velhonoja, Katri Kuuppo, Timo Tamminen, and Jukka Seppälä

Microscopic cyanobacteria, or blue-green algae, are found in a wide range of aquatic environments (freshwater, brackish, and marine). They can create a nuisance due to biomass accumulation and the production of toxins, which can be harmful to humans and other animals. Cyanobacteria exist in a variety of sizes and shapes (Figure $1 \mathrm{a}-\mathrm{c}$ ), and their blue-green coloration (some species are reddish) is attributed to the presence of phycobiliproteins that are the primary light-harvesting pigments for their photosynthesis and that are auto fluorescent (Figure $1 \mathrm{~b}-\mathrm{e}$ ).

When the reactive forms of nitrogen needed by all primary producers for growth are not available in the water, some cyanobacteria can convert free nitrogen $\left(\mathrm{N}_{2}\right)$ into more reactive nitrogen forms (nitrogen fixation) to sustain themselves in conditions that would not support most algal growth.

Blooms of cyanobacteria are a known issue in many parts of the world. In the Baltic Sea they are commonly observed during summer, when biomass accumulations can cover large areas (Figure 1h). Although more than 200 species have been reported, Baltic bloom formation is mainly attributed to a few filamentous species (Figure 1a). As one of the largest brackish water bodies in

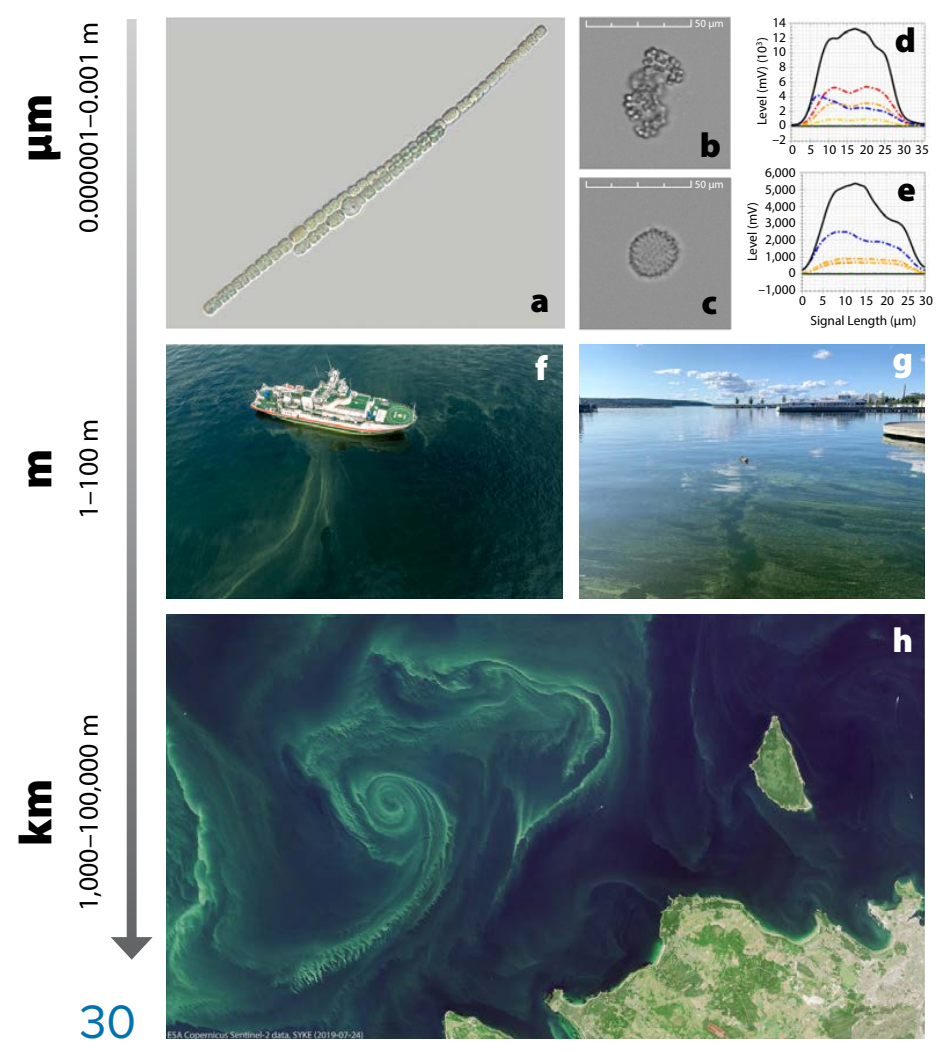

the world, the unique Baltic Sea environment is sensitive to climatic and anthropogenic stressors, such as the excess nutrient loads that result from human activities and lead to eutrophication.

During summer, when reactive forms of nitrogen are scarce, the growth of cyanobacteria is favored by their capacity for fixing $\mathrm{N}_{2}$, by high inorganic phosphorus concentrations in the waters, and by increasing water temperatures. Inefficient zooplankton grazing results in the accumulation of cyanobacteria and affects how nutrients, matter, and energy flow in the environment.

Increased cyanobacteria biomass and surface accumulations serve as indicators of Baltic Sea health. Accumulated cyanobacteria biomass often negatively affects recreation and fisheries, as it can not only be aesthetically displeasing but also poses a real threat for humans and domestic animals due to the potential toxicity. Thus, the detection of cyanobacteria blooms in the Baltic Sea is of paramount importance to the environment, aquatic resources, and human health, and it is needed to manage mitigation.

Systematic observations of cyanobacteria in the Baltic Sea constitute one part of monitoring activities for the larger phytoplankton community that provide environmental quality indicators for the region. Baltic Sea phytoplankton monitoring began in Finland in 1979, with observations limited to 12 offshore locations that were sampled with a research vessel. The phytoplankton monitoring network was expanded to coastal areas in the early 1990s, and today the phytoplankton monitoring network includes 121 locations in waters around Finland (Figure 2a). Phytoplankton cells larger than $2 \mu \mathrm{m}$, including cyanobacteria, are counted and identified using quantitative microscopy, employing the only method that is based on international standards in order to allow comparison of data between countries and provide a basis for implementing new methods. However, this method requires samples to be fixed and an expert for species identification, and it is time consuming (analysis of each sample takes a few hours).

FIGURE 1. Micrographs of different live cyanobacteria were made using (a) bright field light microscopy and (b,c) imaging flow cytometry. $(d, e)$ Optical properties of organisms depicted in (b) and (c) show different pigment compositions (red, yellow, and orange lines). Cyanobacteria surface accumulations are observed (f) with aerial photography, (g) along the coast, and (h) by satellite. The arrow at left indicates the scales and size ranges in which cyanobacteria can be observed, from individual cells to biomass accumulations over extensive areas. Image sources: (a-e): L. Haraguchi. (f) I. Lastumäki. (g) E. Lehtinen. (h) J. Attila 
FIGURE 2. Examples of different methods used for cyanobacteria observation in the Baltic Sea. (a) Map showing Baltic Sea coastal and open sea locations of Finnish phytoplankton monitoring stations. (b) A time series from one of the phytoplankton monitoring stations shows biomass of different cyanobacteria species between 1979 and 2019. (c) True color satellite imagery shows cyanobacteria surface layer accumulation over a large area in summer 2018 (the image area is shown in the black rectangle in (a). The colorful line indicates the concentration of cyanobacteria pigments (phycobilins) recorded with the FerryBox by a ship of opportunity during the same period, with higher concentrations shown in red and lower in blue. (d) A compilation of all FerryBox/ship-of-opportunity trips recorded in 2018 illustrates the variability in space ( $x$-axis) and time (y-axis) of cyanobacteria concentrations. (e) High-resolution time series were recorded at Utö Atmospheric and Marine Research station using the Imaging FlowCytobot (f), an automated in-flow imaging system. Different colors depict different cyanobacteria species. Some examples of the recorded cells: (g) Aphanizomenon flosaquae), (h) Dolichospermum/ Anabaenopsis, and (i) Nodularia spumigena. Measurements at Utö and in FerryBox systems are part of the Pan-European coastal observation network JERICO-RI. Panel (c) ferry photo courtesy Juha-Markku Leppänen

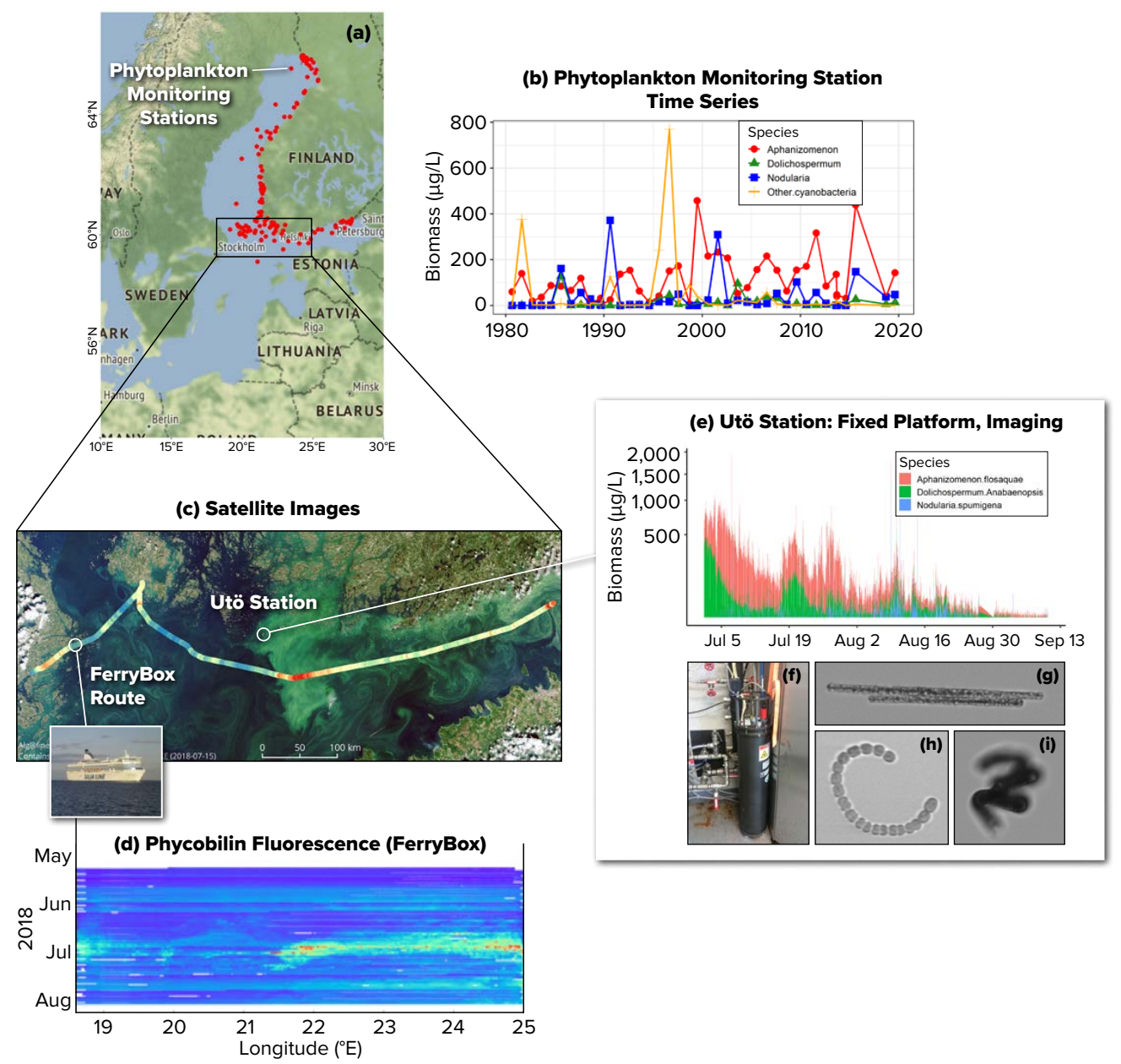

In the early 1990s, the Alg@line program for observations using ships of opportunity was introduced. Commercial Baltic ferry lines are equipped with automated sampling systems called FerryBoxes that collect discrete water samples for laboratory analyses and have sensors for detecting the specific pigment fluorescence of cyanobacteria (Figure 1b-e) in high spatial resolution (Figure 2c,d).

In 1998, summertime national cyanobacterial bloom monitoring was initiated, with bloom intensity estimated visually in lakes, along coasts, and in archipelago areas. Coordinated by Finnish environmental authorities, it engages citizen volunteers and incorporates observations from routine border guard flights.

Satellite observations for detecting the cyanobacteria blooms were established in Finland in 2004, and since 2016, an open web map interface showing the areas of surface layer blooms, true color imagery (Figures $1 \mathrm{~h}$ and $2 \mathrm{c}$ ), and surface water temperatures has been available. Additionally, annual composites that show summer surface blooms detected by satellite observations are generated.

In 2015, the Utö Atmospheric and Marine Research Station was established in the outer Archipelago Sea for continuous, autonomous collection of observations using fluorescence sensors (like those used in FerryBox) and imaging in-flow techniques for identification and quantification of cyanobacteria (Figure 2e-i). Although the in-flow methods allow for fast and reliable analysis of individual particles in a sample, these relatively new methods are still not standardized, so experts are required to adjust the automated classifications and to manage the massive amount of data produced by the continuous measurements.

The evolution of the monitoring network and the broadening of its spatiotemporal coverage has only been possible through the combined efforts of research institutions, international partners, and public participation, as well as the use of a variety of technologies. Multiple techniques can be used to observe cyanobacteria, each with different strengths and weaknesses, and combining techniques improves observation capacity and therefore cyanobacteria monitoring (Figure 2). Network observations are coordinated by the Finnish Environment Institute, which compiles the information as a national summer bloom status report that is made available to the public weekly. The evolution of Finland's Baltic Sea cyanobacteria observations over recent decades illustrates not only the various methods available for observing the ocean but also the importance of engaging diverse partners, including citizens, to accomplish observations of marine phenomena.

ARTICLE DOI: https://doi.org/10.5670/oceanog.2021.supplement.02-13 


\section{AUTHORS}

Lumi Haraguchi (lumi.haraguchi@syke.fi), Sirpa Lehtinen, Jenni Attila, Hanna Alasalmi, Matti Lindholm, Kaisa Kraft, Otso Velhonoja, Katri Kuuppo, Timo Tamminen, and Jukka Seppälä, Finnish Environment Institute (SYKE), Finland.

\section{ARTICLE CITATION}

Haraguchi, L., S. Lehtinen, J. Attila, H. Alasalmi, M. Lindholm, K. Kraft, O. Velhonoja, K. Kuuppo, T. Tamminen, and J. Seppälä. 2021. The evolution of cyanobacteria bloom observation in the Baltic Sea. Pp. 30-31 in Frontiers in Ocean Observing: Documenting Ecosystems, Understanding Environmental Changes, Forecasting Hazards. E.S. Kappel, S.K. Juniper, S. Seeyave, E. Smith, and M. Visbeck, eds, A Supplement to Oceanography 34(4), https://doi.org/10.5670/oceanog.2021.supplement.02-13.

\section{COPYRIGHT \& USAGE}

This is an open access article made available under the terms of the Creative Commons Attribution 4.0 International License (https://creativecommons.org/ licenses/by/4.0/), which permits use, sharing, adaptation, distribution, and reproduction in any medium or format as long as users cite the materials appropriately, provide a link to the Creative Commons license, and indicate the changes that were made to the original content. 